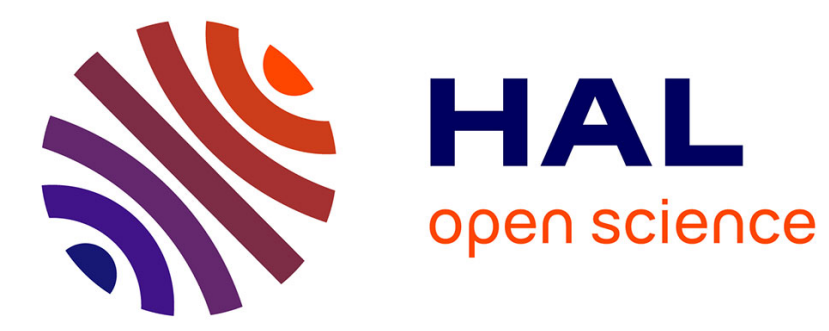

\title{
Preparation and electrical properties of the mixed valency solid solutions $\mathrm{Cr} 1-\mathrm{xNbxWO} 4$
}

Yu Ju Shin, Jean-Pierre Doumerc, Patrice Dordor, Michel Pouchard, Paul Hagenmuller

\section{- To cite this version:}

Yu Ju Shin, Jean-Pierre Doumerc, Patrice Dordor, Michel Pouchard, Paul Hagenmuller. Preparation and electrical properties of the mixed valency solid solutions Cr1-xNbxWO4. Journal of Physics and Chemistry of Solids, 1993, 54 (1), pp.25-30. 10.1016/0022-3697(93)90109-5 . hal-03199680

\section{HAL Id: hal-03199680 \\ https://hal.science/hal-03199680}

Submitted on 15 Apr 2021

HAL is a multi-disciplinary open access archive for the deposit and dissemination of scientific research documents, whether they are published or not. The documents may come from teaching and research institutions in France or abroad, or from public or private research centers.
L'archive ouverte pluridisciplinaire HAL, est destinée au dépôt et à la diffusion de documents scientifiques de niveau recherche, publiés ou non, émanant des établissements d'enseignement et de recherche français ou étrangers, des laboratoires publics ou privés. 


\title{
PREPARATION AND ELECTRICAL PROPERTIES OF THE MIXED VALENCY SOLID SOLUTIONS $\mathrm{Cr}_{1_{-x}} \mathrm{Nb}_{x} \mathrm{WO}_{4}$
}

\author{
Y. J. Shin, J. P. Doumerc, P. Dordor, M. Pouchard and P. Hagenmuller \\ Laboratoire de Chimie du Solide du CNRS, 351, Cours de la Libération, 33405 Talence Cedex, France
}

\begin{abstract}
Mixed valency solid solutions of formula $\mathrm{Cr}_{1-x} \mathrm{Nb}_{x} \mathrm{WO}_{4}$ have been prepared at $1200^{\circ} \mathrm{C}$. Two phases have been identified at room temperature by X-ray diffraction: one with a rutile-related structure of $\mathrm{AlWO}_{4}$-type for $\mathrm{O} \leqslant x \leqslant 0.25$ and another with the tetragonal rutile structure for $0.25<x \leqslant 0.40$. Electrical conductivity and thermoelectric power were measured between room temperature and liquid helium. All solid solutions have a semiconducting behavior. A comparison with the related $\mathrm{Cr}_{1-x} \mathrm{~W}_{1+x} \mathrm{O}_{4}$ system suggests that in the $\mathrm{Cr}_{1-x} \mathrm{Nb}_{x} \mathrm{WO}_{4}$ system electrons are localized within $\mathrm{W}-\mathrm{W}$ dimers as a result of a too large a dimer-dimer separation.
\end{abstract}

Keywords: Chromium niobium tungsten (V) oxide, metal-metal pairs, mixed valence oxides, electrical properties, metal-non metal transition.

\section{INTRODUCTION}

Ternary tungsten oxides of formula $\mathrm{A}^{3+} \mathrm{W}^{5+} \mathrm{O}_{4}$ $(\mathrm{A}=\mathrm{Al}, \mathrm{Cr}, \mathrm{Ga})$ exhibit a monoclinic symmetry $[1,2]$ with a rutile-derived structure [3]. The $5+$ oxidation state, unusual for tungsten in oxides, is stabilized by the formation of $\mathrm{W}-\mathrm{W}$ bonds across the common edges of $\mathrm{WO}_{6}$ octahedra forming chains parallel to the $[001]_{R}$ axis. These chains alternate along $[110]_{R}$ with analogous chains containing the $A^{3+}$ ions. This structure is close to that of $\mathrm{Cr}_{x} \mathrm{~V}_{1-x} \mathrm{O}_{2}$ $(0.013 \leqslant x \leqslant 0.08)$ [4]. Many $\mathrm{MO}_{2}(\mathbf{M}=\mathrm{V}, \mathrm{Nb}, \mathbf{M o}$, etc.) oxides have related structures with slightly different arrangements of the $\mathbf{M}-\mathbf{M}$ bonds $[2,3]$. The $d$-electrons of $\mathrm{W}^{5+}$ ions are trapped in homopolar $\mathrm{W}-\mathrm{W}$ bonds, so that the $\mathrm{AWO}_{4}$ oxides are semiconductors. However, the partial reduction of $\mathbf{W}^{5+}$ cations giving rise to a mixed valence state can lead to an insulator-to-metal transition as detected, for instance, in the $\mathrm{Cr}_{1-x} \mathrm{~W}_{1+x} \mathrm{O}_{4}$ solid solutions $[5,6]$.

Actually, in such a solid solution, two important electronic transport determining parameters vary simultaneously, i.e. the average oxidation state and the concentration of tungsten atoms. It makes particularly difficult the interpretation of the transport properties, even though we can anticipate that a minimum tungsten concentration is necessary to achieve electronic delocalization.

Therefore, it seemed worthwhile to investigate the influence of the $W^{4+} / W^{5+}$ ratio in a system where the overall concentration of tungsten would remain constant. Such conditions could be fulfilled in $\mathrm{Cr}_{1-x} \mathrm{Nb}_{x} \mathrm{WO}_{4}$ solid solutions in which the substi- tution of $\mathrm{Cr}^{3+}$ ions by $\mathrm{Nb}^{5+}$ ions should be accompanied by the partial reduction of $\mathrm{W}^{5+}$ into $\mathrm{W}^{4+}$.

The present paper describes the preparation and characterization of $\mathrm{Cr}_{1-x} \mathrm{Nb}_{x} \mathrm{WO}_{4}$ solid solutions and discusses the electrical properties.

\section{EXPERIMENTAL CONDITIONS}

The $\mathrm{Cr}_{1-x} \mathrm{Nb}_{x} \mathrm{WO}_{4}$ solid solutions have been synthesized by direct solid state reactions from $\mathrm{Cr}_{2} \mathrm{O}_{3}$, $\mathrm{Nb}_{2} \mathrm{O}_{5}$, $\mathrm{WO}_{3}$ and metallic $\mathrm{W}$, according to the following reactional scheme:

$$
\begin{array}{r}
(1-x) / 2 \mathrm{Cr}_{2} \mathrm{O}_{3}+x / 2 \mathrm{Nb}_{2} \mathrm{O}_{5}+(5-2 x) / 6 \mathrm{WO}_{3} \\
+(1+2 x) / 6 \mathrm{~W} \rightarrow \mathrm{Cr}_{1-\mathrm{r}} \mathrm{Nb}_{\mathbf{x}} \mathrm{WO}_{4} .
\end{array}
$$

Homogeneous mixtures of starting materials were pelletized and introduced into silica tubes $(\phi=10 \mathrm{~mm})$, which were sealed under low pressure $(\sim 10 \mathrm{~Pa})$. The tubes were heated at $1200^{\circ} \mathrm{C}$ for $24 \mathrm{~h}$ and then quenched by dropping into water. The same procedure was repeated and after each treatment the obtained products were examined by $\mathrm{X}$-ray diffraction. Reactions were completed usually after three or four thermal treatments.

Powder X-ray diffractograms have been obtained using a Philips 1050 diffractometer with a copper anticathode. Lattice constants were determined thanks to a least square method from $d$-values corrected using silicon as an internal standard $\left(a=5.4305 \AA\right.$ at $25^{\circ} \mathrm{C}$ ).

Electrical conductivity measurements were performed on pellets sintered at $1200^{\circ} \mathrm{C}$ (compactness 


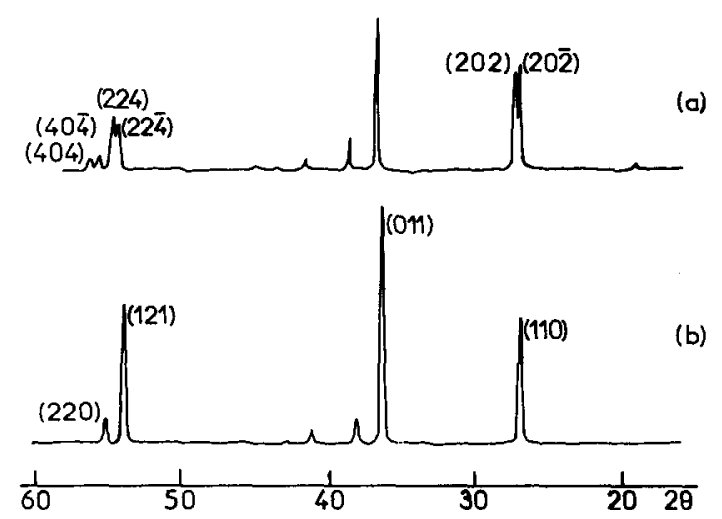

Fig. 1. X-ray diffractograms of $\mathrm{Cr}_{0.7} \mathrm{Nb}_{0.3} \mathrm{WO}_{4}$ quenched from $1050^{\circ} \mathrm{C}$ (a), and from $1200^{\circ} \mathrm{C} \mathrm{(b)}$.

$\simeq 70 \% ; \phi=5 \mathrm{~mm}$ ) by using a conventional fourprobe method [7]. Thermoelectric power data were obtained using an equipment described elsewhere [8].

\section{RESULTS AND DISCUSSION}

\subsection{Structural evolution}

$\mathrm{CrWO}_{4}$ is isostructural with $\mathrm{AlWO}_{4}$ (space group $C_{2 / m}$ ) [1]. The lattice constants of the monoclinic lattice $(a=9.220 \AA, b=5.844 \AA, c=9.262 \AA$ and $\beta=91.95^{\circ}$ ) are in good agreement with those previously reported by some of us [5].

For the samples heated at $1200^{\circ} \mathrm{C}$ and quenched, we have obtained two phases, successively, as $x$ increases: a monoclinic M-phase isostructural with $\mathrm{CrWO}_{4}$ for $0 \leqslant x \leqslant 0.25$ and a tetragonal $\mathrm{R}$-phase of rutile structure for $0.25<x \leqslant 0.40$. For $x>0.4$, $\mathrm{Cr}_{0.6} \mathrm{Nb}_{0.4} \mathrm{WO}_{4}$ coexists with niobium and tungsten oxides. The long range ordering of $\mathrm{W}-\mathrm{W}$ pairs should remain in the $M$-phase with two distinguishable kinds of chains, but in the R-phase, the W-W pairs are either randomly distributed in the lattice or no longer exist.

Annealing the products at $1050^{\circ} \mathrm{C}$ followed by quenching shows that only $\mathrm{Cr}_{0.7} \mathrm{Nb}_{0.3} \mathrm{WO}_{4}$ undergoes

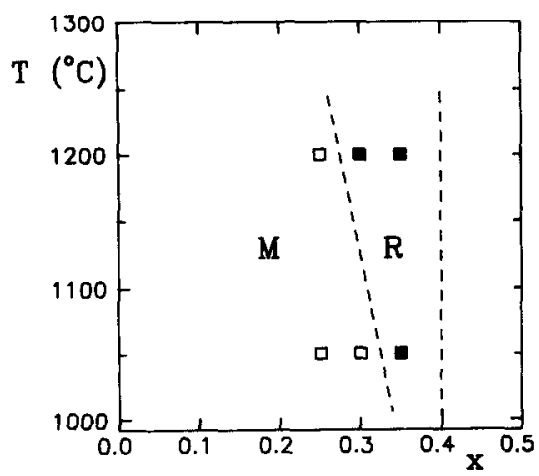

Fig. 2. Tentative phase diagram of $\mathrm{Cr}_{1-x} \mathrm{Nb}_{x} \mathrm{WO}_{4}$ for $1050^{\circ} \mathrm{C} \leqslant T \leqslant 1200^{\circ} \mathrm{C}$

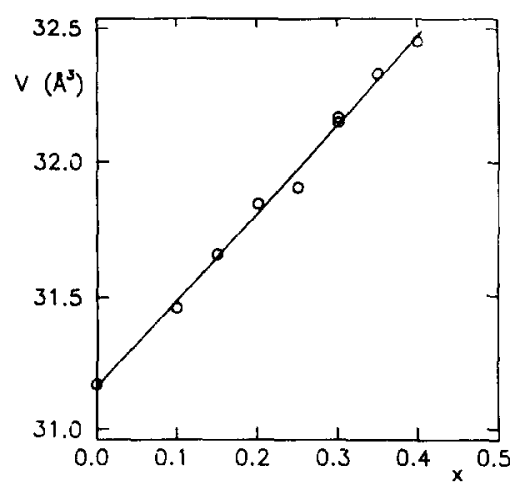

Fig. 3. Variation of the reduced cell volume (volume/MO unit) with $x$ for the $\mathrm{Cr}_{1-x} \mathrm{Nb}_{x} \mathrm{WO}_{4} \mathrm{M}$-phase (filled circles) and R-phase (open circles). For $x=0.3$ the M-phase has been obtained by annealing at $1050^{\circ} \mathrm{C}$ (see text). Other data are for samples quenched from $1200^{\circ} \mathrm{C}$.

a reversible $M \rightleftharpoons R$ transition as evidenced by the splitting of the (110), (121) and (220) peaks as shown in Fig. 1, suggesting the partial phase diagram of Fig. 2.

The increase of the cell volume (Fig. 3) can be ascribed to that of the ionic radii $\left(r_{\mathrm{Cr}^{3}+}=0.615 \AA\right.$, $r_{\mathrm{W} s^{+}}=0.62 \AA, r_{\mathrm{Nb} s_{+}}=0.64 \AA, r_{\mathrm{W} 4+}=0.66 \AA$ in octahedral site [9]) as niobium is substituted for chromium following the equation

$$
\mathrm{Cr}^{3+}+2 \mathrm{~W}^{5+} \rightarrow \mathrm{Nb}^{5+}+2 \mathrm{~W}^{4+}
$$

where we suppose that $\mathrm{Nb}^{5+}$ is not reduced by $\mathrm{W}^{4+}$ as shown below (see section 3.2).

However this expansion of the unit cell volume does not involve a simultaneous increase of all the parameters as can be seen in Fig. 4. The $a_{\mathrm{M}}$ and $c_{\mathrm{M}}$ constants of the M-phase increase linearly with $x$ and tend to the same value for $x=0.25$, and $\beta_{\mathrm{M}}$ tends simultaneously to $90^{\circ}$ without reaching this value.

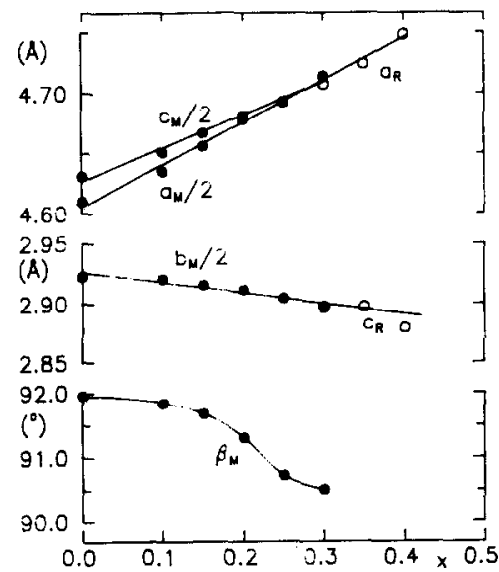

Fig. 4. Variation of the lattice constants with $x$ for the $\mathrm{Cr}_{1-x} \mathrm{Nb}_{x} \mathrm{WO}_{4} \mathrm{M}$-phase (filled circles) and $\mathrm{R}$-phase (open circles). For $x=0.3$ the M-phase is obtained by annealing at $1050^{\circ} \mathrm{C}$ (see text). Other data are for samples quenched from $1200^{\circ} \mathrm{C}$. 


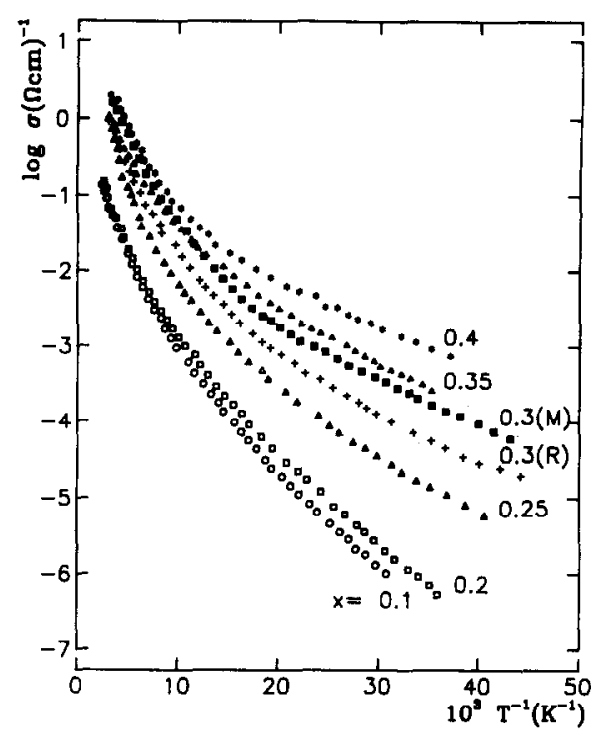

Fig. 5. Logarithm of the electrical conductivity of $\mathrm{Cr}_{1-x} \mathrm{Nb}_{x} \mathrm{WO}_{4}$ vs reciprocal temperature.

For the R-phase, $a_{\mathrm{R}}$ also increases with $x$. Conversely, the $b_{\mathrm{M}}$ and $c_{\mathrm{R}}$ parameters decrease as $x$ increases. Two effects can explain such a behavior of the $b_{M}$ and $c_{R}$ constants which correspond to the direction in which the octahedra are sharing edges. First, as $x$ increases, the number of $5 d$ electrons per tungsten atom is enhanced, leading to shortening of the $\mathbf{W}-\mathbf{W}$ distance by formation of multiple bonds [3]. Simultaneously, the decreasing effective charge of the tungsten atoms reduces the electrostatic repulsion between them [5].

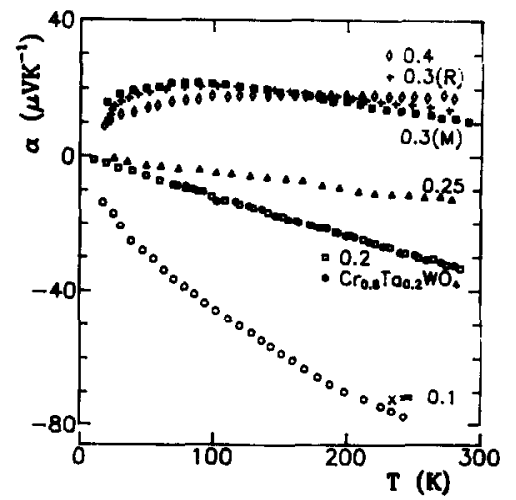

Fig. 6. Variation of the thermoelectric power of $\mathrm{Cr}_{1-x} \mathrm{Nb}_{x} \mathrm{WO}_{4}$ as a function of temperature.

\subsection{Electrical properties}

Figure 5 gives the variation of the logarithm of electrical conductivity $\sigma$ vs $T^{-1}$ for polycrystalline samples of $\mathrm{Cr}_{1-x} \mathrm{Nb}_{x} \mathrm{WO}_{4}(x=0,0.1,0.2,0.25,0.30$, $0.35,0.4)$. All samples are semiconductors. The monoclinic form of $\mathrm{Cr}_{0.7} \mathrm{Nb}_{0.3} \mathrm{WO}_{4}$ exhibits slightly higher conductivity than the tetragonal one. For $\mathrm{CrWO}_{4}$ the thermoelectric power is negative and its absolute value increases with temperature, reaching a large value at room temperature $\left(\alpha=-500 \mu \mathrm{VK}^{-1}\right)$. However $|\alpha|$ becomes much smaller as soon as substitution occurs (Fig. 6). For $0.1 \leqslant x \leqslant 0.25, \alpha$ is negative and decreases linearly with increasing temperature and $|\alpha|$ decreases with increasing $x$. For $x=0.3, \alpha$ is positive and the thermal behavior is no longer linear, exhibiting a broad maximum at

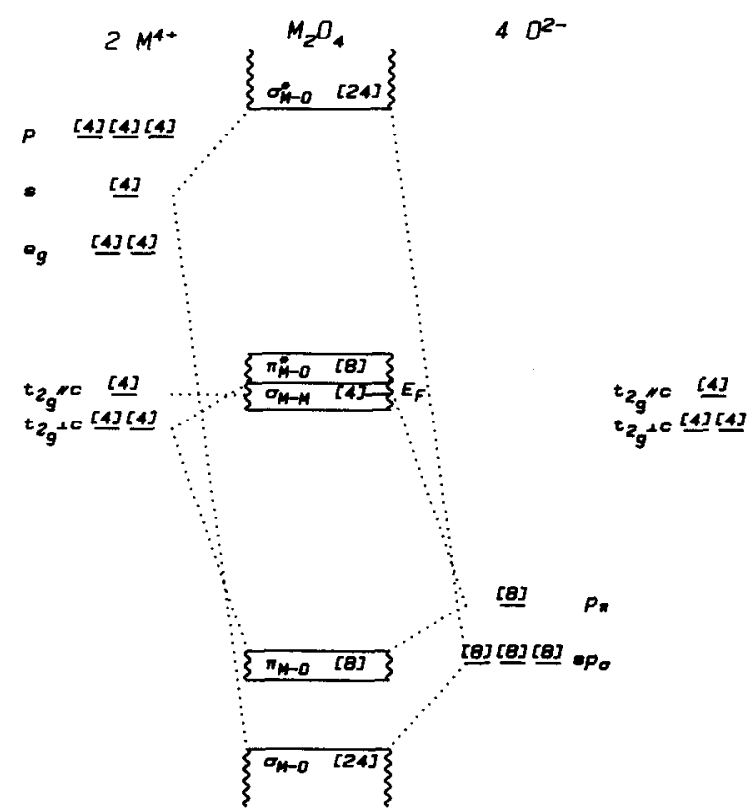

(a)
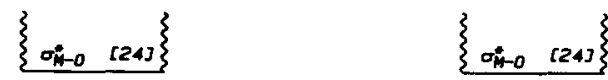

Fig. 7. Schematic one-electron energy diagrams for rutile and rutile-related $\mathrm{MO}_{2}$ dioxides with one $d$-electron per cation without formation (a), and with formation (b), of $\mathbf{M - M}$ pairs. Diagram for two $d$-electrons with formation of $\pi$-bonds (c). 
$\sim 100 \mathrm{~K}$. The behavior is exactly the same for the two forms of $\mathrm{Cr}_{0.7} \mathrm{Nb}_{0.3} \mathrm{WO}_{4}$. For $x=0.4, \alpha$ is temperature-independent above $140 \mathrm{~K}$.

3.2.1. Energy diagram. The electronic transport properties in transition element oxides of rutile-type structure containing metal-metal bonds have given rise to numerous theoretical and experimental research during the last 20 years $[3,10-13]$. For example, $\mathrm{VO}_{2}$ and the related solid solutions with a $d^{1}$ configuration have been intensively studied $[14,15]$. It is now well known that the transport properties in such systems strongly depend on the formation and dissociation of metal-metal bonds.

Goodenough $[10,11]$ has proposed a schematic energy diagram for $\mathrm{VO}_{2}$-type compounds taking into account $\mathrm{M}-\mathrm{M}$ pairing. Later, Rogers et al. [3] extended this diagram to transition elements having more than one $d$-electron and they proposed the formation of multiple $(\sigma+\pi)$ bonds. A simple band diagram for the tetragonal rutile-type oxides $\mathrm{MO}_{2}$ is sketched in Fig. 7a. With one $d$-electron per M-cation the Fermi level should lie in the middle of the $\sigma_{M-M}$ band. Formation of metal-metal bonds leads to splitting of the $\sigma_{\mathrm{M}-\mathrm{M}}$ band. In a similar way the $\pi_{\mathrm{M}-\mathrm{O}}^{*}$ band splits into a lower band which has a bonding character with respect to the $\mathrm{M}-\mathrm{O}-\mathrm{M}$ interactions and an upper band which is antibonding with regard to the $\mathbf{M}-\mathrm{O}-\mathbf{M}$ interactions as illustrated in Fig. $7 \mathrm{~b}$. Figure 7c takes also into account the formation of $\pi_{\mathrm{w}-\mathrm{w}}$ bonds. In order to apply these band diagrams to our solid solutions, we shall assume that the $\mathrm{Cr}^{3+}$ $d$-electrons are strongly localized and, as argued below, a $d^{\circ}$ configuration for the $\mathrm{Nb}$-atoms (i.e. $\mathrm{Nb}^{5+}$ ions). With such an approach we have only to consider the energy bands arising from the combination of tungsten and oxygen orbitals. In order to follow the filling rate of the energy bands and to make comparisons with related systems such as $\mathrm{Cr}_{1-x} \mathrm{~W}_{1+x} \mathrm{O}_{4}$ we shall assume that the number of available electronic levels in each band is determined by the number of tungsten atoms per $\mathrm{AMO}_{4}$ formula unit.

3.2.2. Monoclinic phase. With one $d$-electron per $\mathrm{W}^{\mathrm{s+}}$-ion, the electronic state of $\mathrm{CrWO}_{4}$ is analogous to that of $\mathrm{VO}_{2}$ (Fig. 7b). The conductivity and thermoelectric power data suggest that the conduction is due to extrinsic electrons occupying the bottom of the conduction band and moving by hopping, as discussed in a previous work [6].

In order to discuss the electrical properties of $\mathrm{Cr}_{1-x} \mathrm{Nb}_{x} \mathrm{WO}_{4}$ solid solutions it is necessary to know whether $d$-electrons belong to niobium or tungsten orbitals. In other words we have to consider how the redox equilibrium is shifted

$$
\mathrm{Nb}^{5+}+\mathrm{W}^{4+} \rightleftarrows \mathrm{Nb}^{4+}+\mathrm{W}^{5+} .
$$

Magnetic properties are not useful for that purpose as: (i) the $\mathrm{W}^{4+}$ and $\mathrm{Nb}^{4+}$ effective moments in such a matrix are not well known and it would be hazardous to imagine how they differ and (ii) $\mathrm{Cr}^{3+}$ ions with $S=3 / 2$ largely contribute to the magnetic susceptibility and would hide the weaker contribution of $\mathrm{Nb}^{4+}$ or $\mathrm{W}^{4+}$ ions.

XPS or X-ray absorption experiments, of course, would probably give direct evidence of the oxidation states of the various cations involved in the materials. However, it was also possible to use a much simpler way for answering the above question, for instance in comparing a physical property sensitive to carrier-density such as the thermoelectric power for a niobium-substituted and a tantalumsubstituted $\left(\mathrm{Cr}_{1-x} \mathrm{Ta}_{x} \mathrm{WO}_{4}\right)$ sample. Actually the analogue of equilibrium (2) for tantalum is completely displaced to the left-hand side since, as it is well known, $\mathrm{Ta}^{4+}$ is particularly unstable in oxides where it has never been found to coexist in significant amounts with $\mathrm{W}^{5+}$.

Thermoelectric power of $\mathrm{Cr}_{0.8} \mathrm{Nb}_{0.2} \mathrm{WO}_{4}$ and $\mathrm{Cr}_{0.8} \mathrm{Ta}_{0.2} \mathrm{WO}_{4}$ are compared in Fig. 6. As they have exactly the same values in the whole temperature range and taking into account the above considerations, we may conclude that equilibrium (2) is also displaced to the left-hand side, and the formula of the solid solutions can be expressed as:

$$
\mathrm{Cr}_{1-x}^{3+} \mathrm{Nb}_{x}^{5+} \mathbf{W}_{1-2 \mathrm{r}}^{5+} \mathbf{W}_{2 x}^{4+} \mathrm{O}_{4}
$$

In section 3.1 we have attributed the decrease of the $b_{\mathrm{M}}$ lattice constant to the formation of multiple bonds, i.e. of $\pi_{M-M}$ bonds in addition to the usual $\sigma_{M-M}$ bonds, leading to the energy diagram of Fig. $7 \mathrm{c}$. It explains the insulating behavior resulting from a trapping of the $d$-clectrons in such $\mathrm{W}-\mathrm{W}$ pairs. The lincar increase of $|\alpha|$ vs $T$ shows that the mobility $\mu$ is thermally activated rather than the charge carrier density. In such a case $\alpha$ is given by the usual formula [16]:

$$
\alpha=\frac{\pi^{2} k^{2} T}{3 e}\left[\frac{\mathrm{d} \ln \sigma(E)}{\mathrm{d} E}\right]_{E_{F}} .
$$

The number of $\sigma_{\mathrm{W}-\mathrm{w}}$ and $\pi_{\mathrm{W} \text { w }}$ orbitals is equal to 0.5 per $\mathrm{Cr}_{\mathrm{I}_{-x}} \mathrm{Nb}_{x} \mathrm{WO}_{4}$ formula unit and the number of energy levels is therefore equal to 1 for each of thern. The number of $d$-electrons is equal to $1+2 x$ so that the $\pi_{\mathrm{w}-\mathrm{w}}$ level will be half-filled, for instance when $x=0.25$. Therefore, $\alpha$ must be expected to be negative for $\alpha<0.25$, which is actually observed. As $x$ increases, the Fermi level moves upwards, the density of states at the Fermi level $N\left(E_{F}\right)$ increases and the absolute value of the slope $|\mathrm{d} \alpha / \mathrm{d} T|$ decreases, as experimentally observed (Fig. 6). 
Table 1. Comparison of atomic and electronic densities between the $\mathrm{Cr}_{1-x} \mathrm{Nb}_{x} \mathrm{WO}_{4}$ and

\begin{tabular}{|c|c|c|c|c|c|c|c|c|}
\hline \multirow[b]{2}{*}{$x$-value } & \multicolumn{5}{|c|}{$\mathrm{Cr}_{1-x} \mathrm{Nb}_{x} \mathrm{WO}_{4}$} & \multicolumn{3}{|c|}{$\mathrm{Cr}_{1-x} \mathrm{~W}_{1+x} \mathrm{O}_{4}$} \\
\hline & $x$ & 0.3 & 0.4 & $(0.5)$ & $x$ & $(0.3)$ & 0.4 & 0.5 \\
\hline $\begin{array}{l}\text { Oxidation } \\
\text { state of } \mathbf{W}\end{array}$ & $5-2 x$ & 4.4 & 4.2 & 4.0 & $\frac{5+3 x}{1+x}$ & 4.5 & 4.4 & 4.3 \\
\hline $\begin{array}{l}\text { Number of } \\
d \text {-electrons } \\
\text { per } \mathrm{AWO}_{4} \text { unit }\end{array}$ & $1+2 x$ & 1.6 & 1.8 & 2.0 & $1+3 x$ & 1.9 & 2.2 & 2.25 \\
\hline $\begin{array}{l}\text { Number of W-atoms } \\
\text { per } \mathrm{AWO}_{4} \text { unit }\end{array}$ & 1 & 1 & 1 & 1 & $1+x$ & 1.3 & 1.4 & 1.5 \\
\hline $\begin{array}{l}d \text {-electrons } \\
\text { per W-atom }\end{array}$ & $1+2 x$ & 1.6 & 1.8 & 2.0 & $\frac{1+3 x}{1+x}$ & 1.46 & 1.57 & 1.67 \\
\hline $\begin{array}{l}\text { W-atom } \\
\text { density }\left(10^{22} \mathrm{~cm}^{-3}\right)\end{array}$ & $\frac{Z}{V(x)}$ & 1.55 & 1.54 & - & $\frac{Z(1+x)}{V(x)}$ & - & 2.17 & 2.31 \\
\hline
\end{tabular}

For $x=0.3, \alpha$ is positive but its variation is no longer linear and even $\alpha$ slightly decreases as $T$ increases. Such a complex behavior could be caused by thermal excitation of electrons from the $\pi_{\mathrm{w}-\mathrm{W}}$ levels into the $\pi_{W-0}^{*}$ band (Fig. 7c). The conduction process should be yet dominated by hole hopping as $\alpha$ remains positive. However, the hole concentration in the $\pi_{\mathrm{w}-\mathrm{w}}$ levels and the electron concentration in the $\pi_{\mathrm{w}-\mathrm{o}}^{*}$ band increase with rising temperature, leading to a gradual decrease of $\alpha$ above $100 \mathrm{~K}$ (Fig. 6).

The insulating character of the M-phase can be attributed to a too large a distance between $\mathbf{W}-\mathbf{W}$ dimers preventing the electronic delocalization in a very narrow $\pi_{\mathrm{W}-\mathrm{w}}$ or $\pi_{\mathrm{w}-\mathrm{o}}^{*}$ band. $\dagger$ The $1 \mathrm{D}$-character of such bands as well as the Anderson localization [16] arising from a random distribution of $\mathrm{Cr}$ - and $\mathrm{Nb}$-atoms should also favor localization of charge carriers.

3.2.3. Tetragonal phase. For $x=0.3$, the electrical behavior of the quenched tetragonal phase is very similar to that of the monoclinic phase. The positive value of $\alpha$ may be explained using the diagram of Fig. $7 \mathrm{a}$ as well as that of Fig. 7c. The semiconducting behavior suggests that in the R-phase the charge carriers remain localized in $W-W$ pairs although XRD no longer reveals any long range ordering.

The behavior of the $\mathrm{Cr}_{1-x} \mathrm{Nb}_{x} \mathrm{WO}_{4}$ system contrasts with that of $\mathrm{Cr}_{1-x} \mathrm{~W}_{1+x} \mathrm{O}_{4}$ in which a rutiletype phase was also found but exhibited a metallic-type behavior. The compositional and electronic features of the two systems have been compared in Table 1. They mainly differ by the $\mathrm{W}$-concentration which is much smaller (by about $30 \%$ ) in the present system. This seems to lead to a localization of charge carriers in randomly distributed $\mathbf{W}-\mathbf{W}$ pairs giving rise, for instance, to

†The structural distortion is not responsible for the insulating character, i.e. the localization is not due to a Peierls type transition, as the number of electrons per atoms is not an integer. a temperature-independent thermoelectric power for $x=0.4$ above $100 \mathrm{~K}$ (Fig. 6). The existence of $\mathrm{W}-\mathrm{W}$ pairs in the $\mathrm{R}$-phase is also supported by the monotonous variation of the lattice-constants through the phase transition at $x=0.3$ as illustrated in Fig. 4. Anderson localization arising from a random distribution of $\mathbf{W}-\mathbf{W}$ pairs and of $\mathrm{Cr}^{3+}$ and $\mathrm{Nb}^{5+}$ ions should also strengthen the localization of the carriers. The nonlinear dependence of $\log \sigma$ vs $T^{-1}$ could result from a variable range hopping at low temperature as suggested by the linear variation of $\log \sigma$ vs $T^{-1 / 4}$ according to the well-known Mott law (Fig. 8) [16].

\section{CONCLUSIONS}

Two phases have been found in the $\mathrm{Cr}_{1-x} \mathrm{Nb}_{x} \mathrm{WO}_{4}$ system: a monoclinic phase isostructural with $\mathrm{CrWO}_{4}$ $\left(0 \leqslant x \leqslant 0.25\right.$ at $\left.1200^{\circ} \mathrm{C}\right)$ and a tetragonal phase of rutile-type $\left(0.3 \leqslant x \leqslant 0.4\right.$ at $\left.1200^{\circ} \mathrm{C}\right)$. Both phases are semiconductors and the electrical conduction is mainly due to a hopping mechanism. This result suggests that in the rutile phase holes remain localized in $\mathrm{W}-\mathrm{W}$ pairs randomly distributed. Comparison of the present system with $\mathrm{Cr}_{1-x} \mathrm{~W}_{1+x} \mathrm{O}_{4}$, which exhibits

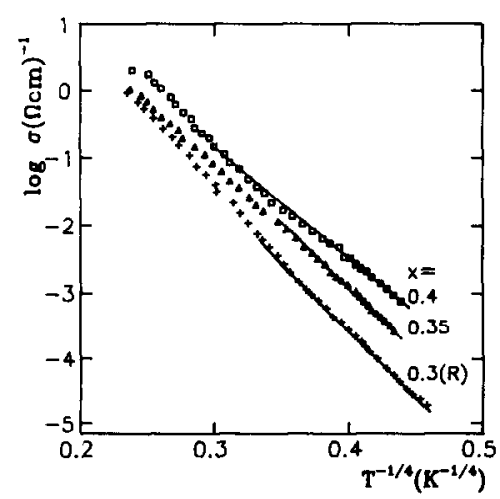

Fig. 8. Variation of the logarithm of the electrical conductivity of $\mathrm{Cr}_{1-x} \mathrm{Nb}_{x} \mathrm{WO}_{4}$ vs $T^{-1 / 4}$. 
a metallic rutile phase for $0.4 \leqslant x \leqslant 0.5$, leads to the conclusion that a lower $\mathrm{W}$-concentration and hence too large W-W distances (between pairs) hinder electronic delocalization in the $\mathrm{Cr}_{1-x} \mathrm{Nb}_{x} \mathrm{WO}_{4}$ solid solutions.

Acknowledgement-One of the authors (Y. J. Shin) is grateful for the financial support of the Sunkyong Magnetics, Ltd. (Seoul, ROK).

\section{REFERENCES}

1. Doumerc J. P., Vlasse M., Pouchard M. and Hagenmuller P., J. Solid State Chem. 14, 144 (1975).

2. Vlasse M., Doumerc J. P., Peshev P., Chaminade J. P. and Pouchard M., Rev. Chim. Miner. 13, 451 (1976).

3. Rogers D. B., Shannon R. D., Sleight A. W. and Gillson J. L., Inorg. Chem. 8, 841 (1969) and references therein

4. Marezio M., McWhan D. B., Remeika J. P. and Dernier P. D., Phys. Rev. B5, 2541 (197I).
5. Wang Y. S., Ellis B., Doumerc J. P., Pouchard M. and Hagenmuller P., $Z$. anorg. allg. Chem. 569, 153 (1989).

6. Doumerc J. P., Wang Y. S., Dordor P., Marquestaut E., Pouchard M. and Hagenmuller P., J. Phys. Chem. Solids 51, 467 (1990).

7. Dordor P., Marquestaut E., Salducci C. and Hagenmuller P., Rev. Phys. Appl. 20, 795 (1985).

8. Dordor P., Marquestaut E. and Villeneuve G., Rev. Phys. Appl. 15, 1607 (1980).

9. Shannon R. D., Acta Cryst. A32, 751 (1976).

10. Goodenough J. B., Bull. Soc. Chim. Fr. 4, 1200 (1965).

11. Goodenough J. B., Preg. Solid State Chem. 5, 145 (1971).

12. Poumellec B. and Marucco J. F., J. Phys. Chem. Solids 46, 71 (1985).

13. Ravindran Nair K., Greenblatt $M$. and McCarroll W. H., Mat. Res. Bull. 18, 309 (1983)

14. Drillon M. and Villeneuve G., Mat. Res. Bull. 9, 1199 (1974).

15. Fisher B., J. Phys. Chem. Solids 43, 205 (1982).

16. Mott N. F. and Davis E. A., Electronic Processes in Noncrystalline Materials, 2nd edition. Clarendon Press, Oxford (1979). 